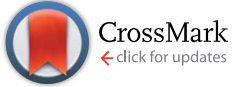

Cite this: RSC Adv., 2017, 7, 3282

Received 1st November 2016 Accepted 1st December 2016

DOI: 10.1039/c6ra26159k

www.rsc.org/advances

\section{Stabilization and transformation of Pt nanocrystals supported on $\mathrm{ZnAl}_{2} \mathrm{O}_{4}$ spinel $\dagger$}

\author{
Wei-Zhen Li, $\ddagger^{a}$ Libor Kovarik, ${ }^{a}$ Yingwen Cheng, ${ }^{a}$ Lei Nie, ${ }^{a}$ Mark E. Bowden, ${ }^{a}$ Jun Liu ${ }^{* a}$ \\ and Yong Wang ${ }^{\star a b}$
}

The role of interfacial interaction on the stabilization and transformation of Pt nanocrystals supported on zinc aluminate $\left(\mathrm{ZnAl}_{2} \mathrm{O}_{4}\right)$ was systematically studied in this work. In addition to the remarkable stability of Pt nanocrystals supported on the $\{111\} \mathrm{ZnAl}_{2} \mathrm{O}_{4}$ facet under a harsh oxidizing atmosphere, we also identified the phase segregation of $\mathrm{ZnAl}_{2} \mathrm{O}_{4}$ to $\mathrm{ZnO}$ and $\mathrm{Al}_{2} \mathrm{O}_{3}$ and the transformation of Pt to PtZn bimetallic alloy for $\mathrm{Pt}$ supported on other facets. High resolution scanning transmission electron microscopy and $\mathrm{X}$-ray diffraction analyses reveal the phase segregation is associated with a cation migration mechanism associated with replacement of $\mathrm{Zn}^{2+}$ by $\mathrm{Al}^{3+}$ in the spinel structure. This work confirms the strong interfacial interactions between precious metal nanocrystals and that the spinel support is a general mechanism for stabilizing precious metal catalysts, with important implications for the rational design of stable integrated catalysis systems.
Supported precious metal nanocrystals are essential for many industrially important catalytic reactions because of their remarkable activities that are difficult or impossible to achieve with alternative materials. ${ }^{1}$ However, they usually have poor stability under the harsh conditions associated with practical applications especially with high temperatures and oxidizing atmospheres, and readily transform to less reactive particles with much larger sizes. ${ }^{1,2}$ Therefore, the development of effective approaches to stabilize nanocrystals is of critical importance and has been under intensive research in recent years. The stability of supported nanocrystals depends on many factors, including the phase, exposed facts and interfacial molecular structures of the nanocrystal and the support material, and the instability usually involves several mechanisms. For example, supported Pt nanocrystals migrate and aggregate and form large particles with supports such as $\mathrm{Al}_{2} \mathrm{O}_{3}, \mathrm{SiO}_{2}, \mathrm{TiO}_{2}$ and $\mathrm{ZrO}_{2}{ }^{3,4}$ on the other hand, they can also react with the support and form solid solutions with supports such as $\mathrm{MgO}$ and $\mathrm{CeO}_{2}{ }^{5,6}$ Overall, these pathways lead to loss in Pt dispersion and substantial reduction in catalytic activity. The stability of Pt nanocrystals can be enhanced by applying novel supports and/ or manipulating the surface chemistry of the supports. ${ }^{7-14}$

anstitute for Integrated Catalysis, Pacific Northwest National Laboratory, P. O. Box 999, Richland, WA 99352, USA. E-mail: jun.liu@pnnl.gov

${ }^{b}$ The Gene \& Linda Voiland School of Chemical Engineering and Bioengineering, Washington State University, Pullman, WA 99164, USA. E-mail: yong.wang@pnnl.gov $\dagger$ Electronic supplementary information (ESI) available. See DOI: $10.1039 / \mathrm{c} 6 \mathrm{ra} 26159 \mathrm{k}$

\# Present address: State Key Laboratory of Catalysis, Dalian Institute of Chemical Physics, Chinese Academy of Sciences, Dalian, 116023, China. E-mail: weizhenli@ dicp.ac.cn
However, the results are still unsatisfactory and it is still desired for developing effective and general strategies for synthesizing and processing stable precious metal catalysts systems.

We recently reported the remarkable capability of spinel $\mathrm{MgAl}_{2} \mathrm{O}_{4}$ supports on stabilizing Pt nanocrystals with its $\{111\}$ facet during severe aging at $800{ }^{\circ} \mathrm{C}$ in air. ${ }^{15}$ This prior successful demonstration has motivated us to examine a wider range of spinel-precious metal combinations, with the goal of developing rational approaches for ultra-stable precious metal nanocrystals. In fact, we found that in addition to Pt nanocrystals, $\mathrm{Rh}$ and Ir nanocrystals can also be stabilized as small $(1-3 \mathrm{~nm})$ particles using $\mathrm{MgAl}_{2} \mathrm{O}_{4}$ during severe aging $\left(800^{\circ} \mathrm{C}\right.$ in air for 1 week). The underlying mechanism is identified as epitaxial lattice matching between the spinel $\{111\}$ facet and the metal nanocrystals. ${ }^{16}$ In this work, we desire to examine the use of alternative supports with similar lattice characteristics but different surface chemistry, i.e., zinc aluminate $\left(\mathrm{ZnAl}_{2} \mathrm{O}_{4}\right)$ support, so that the potential roles of surface chemistry can be examined. $\mathrm{ZnAl}_{2} \mathrm{O}_{4}$ was selected because it has similar lattice characteristics with $\mathrm{MgAl}_{2} \mathrm{O}_{4}$, (lattice constant of $\mathrm{ZnAl}_{2} \mathrm{O}_{4}$ is $8.0848 \AA$ vs. $8.0831 \AA$ for $\mathrm{MgAl}_{2} \mathrm{O}_{4}$ ) but different surface composition and structure. The synthesis of $\mathrm{ZnAl}_{2} \mathrm{O}_{4}$ spinel and its use as a catalyst support has been studied previously but limited work has been done specifically aimed at examining the support-catalyst interactions and stabilizations. ${ }^{17-21}$

Herein, we report the synthesis of phase-pure $\mathrm{ZnAl}_{2} \mathrm{O}_{4}$ spinel and the stabilization and transformation of Pt nanoparticles on this support under oxidizing and reducing atmosphere at high temperatures. Through systematic analysis of aged and reduced samples with high resolution scanning transmission electron microscopy (HR-STEM) and X-ray diffraction (XRD) analysis, we 

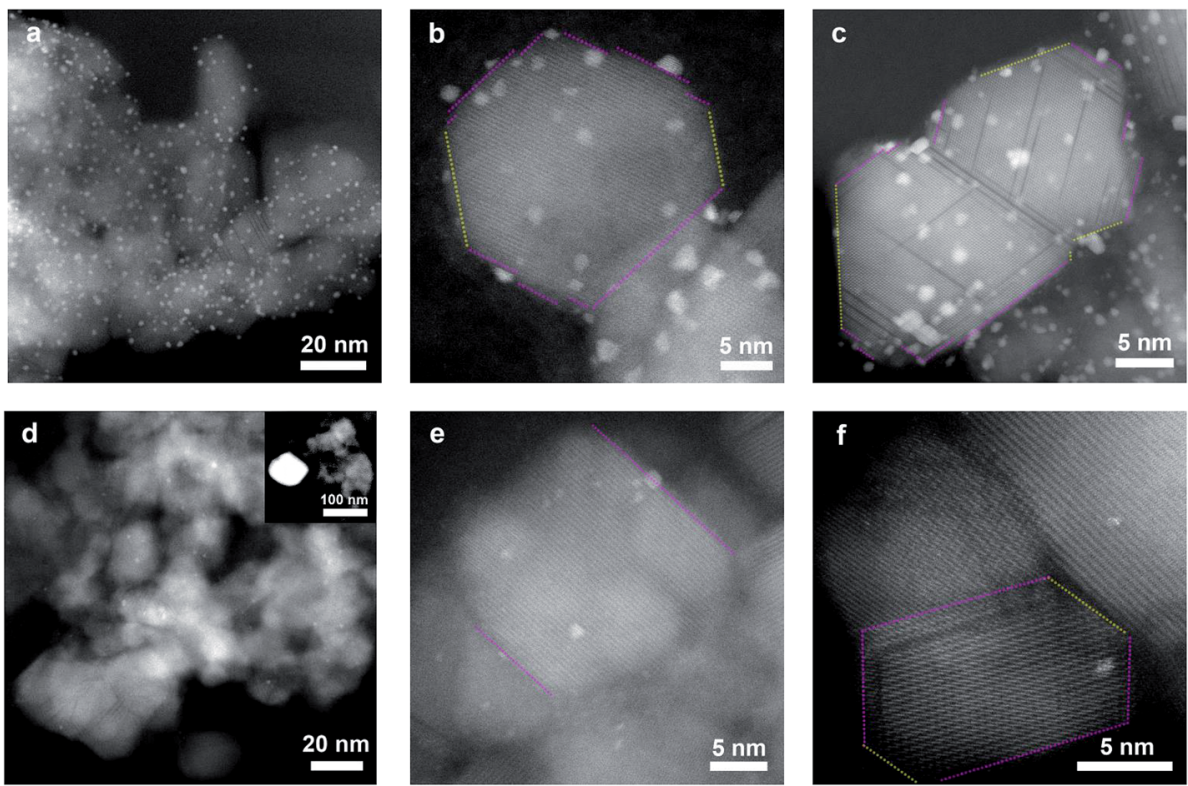

Fig. 1 STEM images of $1 \mathrm{Pt} / \mathrm{ZnAl} \mathrm{O}_{4}-\mathrm{FR}(\mathrm{a}-\mathrm{c})$, and $1 \mathrm{Pt} / \mathrm{ZnAl}_{2} \mathrm{O}_{4}-1 \mathrm{WR}(\mathrm{d}-\mathrm{f})$. The $\{111\}$ and $\{100\}$ facets are marked in magenta and yellow dash lines, respectively.

demonstrate the remarkable stability of small Pt nanocrystals attached on the $\mathrm{ZnAl}_{2} \mathrm{O}_{4}$ spinel $\{111\}$ facet, and the partial phase segregation of $\mathrm{ZnO}$ as well as the formation of PtZn alloys. In practice, phase-pure $\mathrm{ZnAl}_{2} \mathrm{O}_{4}$ spinel was synthesized via an ethanol-mediated controlled hydrolysis method similar to the one reported in our recent papers. ${ }^{15,16}$ Typically, stoichiometric amount of aluminum isopropoxide $(0.1 \mathrm{M})$ and zinc nitrate hexahydrate $(0.05 \mathrm{M})$ were added to $300 \mathrm{ml}$ ethanol with stirring and the mixed solution was heated at $150{ }^{\circ} \mathrm{C}$ (hotplate surface temperature) for 12 hours. The mixture was then dried and the powders obtained were calcined at $800^{\circ} \mathrm{C}$ for 12 hours. The XRD pattern confirms formation of pure $\mathrm{ZnAl}_{2} \mathrm{O}_{4}$ after calcination without any detectable impurity phases (Fig. 2a). The assynthesized $\mathrm{ZnAl}_{2} \mathrm{O}_{4}$ crystals have the characteristics of welldefined cuboctahedral shape with dominant $\{111\}$ facet, small grain sizes $(\sim 12 \mathrm{~nm}$, Fig. $\mathrm{S} 1 \dagger)$ and high surface areas $\left(110.3 \mathrm{~m}^{2}\right.$ $\mathrm{g}^{-1}$ ) (Table S1 $\dagger$ ). Supported Pt nanocrystals (with a typical loading of $1 \mathrm{wt} \%$ ) were prepared by the incipient wetness impregnation method using desired amount of $\mathrm{PtCl}_{4}$ with water as the solvent (see ESI $\dagger$ for detailed experiment procedure). The sample was dried and then calcined at $500{ }^{\circ} \mathrm{C}$ for 5 hours in air, and was subsequently reduced in $5 \% \mathrm{H}_{2} / \mathrm{He}$ at $800{ }^{\circ} \mathrm{C}$ for 2 hours to obtain the $1 \mathrm{Pt} / \mathrm{ZnAl}_{2} \mathrm{O}_{4}$. The Pt nanocrystals prepared with this method were well dispersed on the surface of $\mathrm{ZnAl}_{2} \mathrm{O}_{4}$ and had a dispersion as high as $40.2 \%$ as determined via $\mathrm{H}_{2}$ chemisorption. In addition, the Pt nanocrystals had diameter mostly less than $3 \mathrm{~nm}$ as revealed with STEM analysis (Fig. 1ac). The high dispersion was further supported with XRD as no obvious diffraction peaks originated from Pt were detected (Fig. 2b and c).

The stability of Pt nanocrystals under oxidizing and reducing atmospheres was studied via high temperature aging and reduction since severe sintering of nanocrystals usually occurs under elevated temperatures. A typical procedure is aging in air at $800{ }^{\circ} \mathrm{C}$ for 1 week and reducing in $5 \% \mathrm{H}_{2} / \mathrm{He}$ at $800{ }^{\circ} \mathrm{C}$ for 2 hours. The aging temperatures and the Pt loadings were systematically examined as will be discussed in detail below. The labeling and discussions of samples were organized as follows since a large number of samples were involved: the calcinated samples were labeled with a suffix "O" whereas the reduced samples were labeled with "R". In addition, the fresh prepared samples had a suffix of " $F$ " and the 1 week aged samples had a suffix of " $1 \mathrm{~W}$ ".

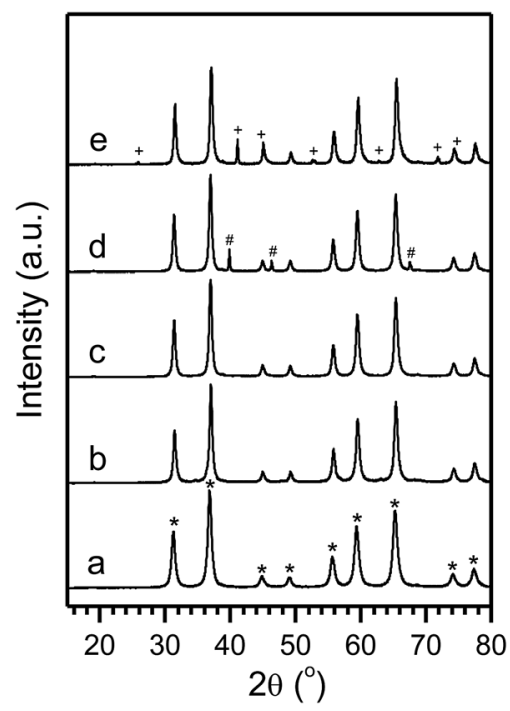

Fig. 2 Set of XRD results: (a) as-synthesized $\mathrm{ZnAl}_{2} \mathrm{O}_{4}$ spinel and 1Pt/ $\mathrm{ZnAl}_{2} \mathrm{O}_{4}$ with different treatment: (b) after calcination at $500{ }^{\circ} \mathrm{C}$ for $5 \mathrm{~h}$ (-FO); (c) reduction at $800^{\circ} \mathrm{C}(-\mathrm{FR})$; (d) aged sample at $800^{\circ} \mathrm{C}$ in air for 1 week (-1WO) and (e) reduced in $\mathrm{H}_{2}$ at $800^{\circ} \mathrm{C}$ for $2 \mathrm{~h}(-1 \mathrm{WR})$. The "*", "\#", and "+" mark indicates diffraction peaks from $\mathrm{ZnAl}_{2} \mathrm{O}_{4}$ spinel, Pt, and PtZn alloy, respectively. 
The Pt dispersion decreased to $10.4 \%$ with the $\mathrm{ZnAl}_{2} \mathrm{O}_{4}$ support after aging in air at $800{ }^{\circ} \mathrm{C}$ for 1 week (Table S1, $\dagger 1 \mathrm{Pt}$ / $\left.\mathrm{ZnAl}_{2} \mathrm{O}_{4}-1 \mathrm{WR}\right)$. This decrease in dispersion is similar to the results observed with the $\mathrm{MgAl}_{2} \mathrm{O}_{4}$ support but is much better than other conventional supports such as $\mathrm{Al}_{2} \mathrm{O}_{3} \cdot{ }^{22}$ The aged sample was then analyzed with STEM and XRD (Fig. 1 and 2). The diameter of $\mathrm{Pt}$ particles after aging and reduction was found to center on the two ranges (therefore a bimodal distribution) of few nanometers similar as prior to aging (1Pt/ $\mathrm{ZnAl}_{2} \mathrm{O}_{4}$-FR, Fig. 1a-c) and much larger sizes of $\sim 80 \mathrm{~nm}$ (Fig. 1d and $\mathrm{S} 3 \dagger$ ). In addition, we observed formation of the PtZn alloy phase (tetragonal, $\mathrm{P} 4 / \mathrm{mmm}$ (123)) by XRD (Fig. 2e). Interestingly, the XRD patterns of the $1 \mathrm{Pt} / \mathrm{ZnAl}_{2} \mathrm{O}_{4}-1 \mathrm{WO}$ sample (after aging but prior to reduction) only exhibited pure metallic $\mathrm{Pt}$ phase. This suggests that the formation of PtZn alloy occurred during the $\mathrm{H}_{2}$ reduction. ${ }^{19,20}$ By using a quantitative multicomponent Rietveld analysis, we estimated that $\sim 70 \%$ of $\mathrm{Pt}$ forms large Pt particles in $1 \mathrm{Pt} / \mathrm{ZnAl}_{2} \mathrm{O}_{4}-1 \mathrm{WO}$ sample, which is in line with the loss in Pt dispersion (from $40.2 \%$ to $10.4 \%$ ) determined via $\mathrm{H}_{2}$ chemisorption as discussed above.

The detailed structures and interactions between $\mathrm{Pt}$ and $\mathrm{ZnAl}_{2} \mathrm{O}_{4}$ both for the fresh and aged samples were further studied with HR-STEM. Fig. 1b shows a typical image for the $1 \mathrm{Pt} / \mathrm{ZnAl}_{2} \mathrm{O}_{4}$-FR sample. Based on the orientation of the spinel crystal, we can determine the exposed facet $(\{111\}$ vs. $\{100\}$, marked with different color in Fig. 1) and therefore the Pt nanoparticle distribution with regard to facet of the support. The loaded Pt particles had particle size of few nanometers and exhibited random distribution on the $\mathrm{ZnAl}_{2} \mathrm{O}_{4}$ spinel facets, suggesting the loading of Pt had no preference on spinel facets during catalyst loading process. After the 1 week aging treatment and the reduction (1Pt/ $\left.\mathrm{ZnAl}_{2} \mathrm{O}_{4}-1 \mathrm{WR}\right)$, small Pt nanocrystals were still observed in the STEM images. Their interaction with the support, however, showed clear preferences and most of the particles were selectively attached on spinel \{111\} facet and had epitaxial relationship with the support. Interestingly, we also noted that the size of Pt particles retained in the aged samples appear smaller than those in the fresh ones, presumably because larger $\mathrm{Pt}$ particles have weaker interaction with the support and are more readily to undergo migration and coalesce during aging. The random occupation of Pt in fresh sample and selective occupation in aged one are also evident in additional HR-STEM images (Fig. S2 and S3†), suggesting that Pt nanocrystals attached on the $\{111\}$ facet has remarkable stability under the conditions examined in this work. These results suggest $\mathrm{ZnAl}_{2} \mathrm{O}_{4}$ spinel also have superb capabilities to stabilize Pt nanoparticles in small sizes even during extremely severe aging. Therefore, taking together the results from $\mathrm{H}_{2}$ chemisorption, STEM and XRD, it was concluded that $\mathrm{ZnAl}_{2} \mathrm{O}_{4}$ spinel had the capability to stabilize Pt nanocrystals similar as $\mathrm{MgAl}_{2} \mathrm{O}_{4}$ spinel and $\mathrm{Pt}$ nanoparticles on spinel $\{111\}$ were stable whereas those on other facets were not. Since these two types of spinel have very similar lattice structure, the origin of the remarkable ability of $\mathrm{ZnAl}_{2} \mathrm{O}_{4}$ spinel $\{111\}$ facet could be rationally understood as the strong interactions between the oxygen termination and platinum $\{111\}$ facet as have been discussed extensively in our previous works with
$\mathrm{MgAl}_{2} \mathrm{O}_{4} \cdot{ }^{15,16}$ Overall, these suggest that the strong epitaxial interaction at the metal-support interfaces is a general stabilization mechanism.

The phase transformation of Pt to PtZn alloy is an interesting phenomenon and was therefore further studied. This transformation is different from observations with $\mathrm{MgAl}_{2} \mathrm{O}_{4}$ support (where only pure Pt phase was observed) under the same conditions. The STEM images reveal fine structures of dark lines in parallel with the spinel (111) plane in the projection of $\mathrm{ZnAl}_{2} \mathrm{O}_{4}$ spinel, which overall appears fault planes in the $1 \mathrm{Pt} /$ $\mathrm{ZnAl}_{2} \mathrm{O}_{4}$-FR sample (Fig. 1c and $\mathrm{S} 2 \dagger$ ). The formation of such dark lines was presumably due to missing of atoms or replacement of heavy atoms by light ones, such as replacement of heavier $\mathrm{Zn}^{2+}$ by lighter $\mathrm{Al}^{3+}$ since the formation energy of antisites of $\mathrm{Zn}^{2+}$ and $\mathrm{Al}^{3+}$ was reported to be small. ${ }^{23,24}$ Considering the fact that $\gamma-\mathrm{Al}_{2} \mathrm{O}_{3}$ has "spinel structure" (cubic, $F d \overline{3} m$ (227), lattice constant: $7.9 \AA$ ) with $\mathrm{Al}^{3+}$ filling both tetrahedral and octahedral sites and the fact that these dark lines didn't generate significant particle fragmentations, the fault planes can be presumably assigned to the replacement of $\mathrm{Zn}^{2+}$ by $\mathrm{Al}^{3+}$ on spinel (111) planes and phase segregation to $\mathrm{ZnO}$ and $\mathrm{Al}_{2} \mathrm{O}_{3}$. These features were also observed for particles after aging experiments, suggesting such structure is relatively stable or the phase segregation had relatively slow kinetics. The replaced $\mathrm{Zn}^{2+}$ cannot be detected as zinc oxide by XRD for all the samples processed with $1 \mathrm{wt} \%$ of $\mathrm{Pt}$ and aged at $800^{\circ} \mathrm{C}$ (Fig. 2), implying that the zinc oxide are very small or highly dispersed in the host spinel.

The formation of fault planes and segregation of $\mathrm{ZnO}$ and $\gamma-\mathrm{Al}_{2} \mathrm{O}_{3}$ from $\mathrm{ZnAl}_{2} \mathrm{O}_{4}$ could decrease the thermal stability of support. Therefore, the thermal stability of the support was subsequently studied systematically and samples were processed with different calcination temperatures and then were analyzed. The spinel was relatively stable at $800{ }^{\circ} \mathrm{C}$ since samples processed at this temperature did not show detectable ZnO phases even after calcining for 1 week (Fig. 2). However, the formation of $\mathrm{ZnO}$ phase was evident with calcination temperature higher than $900{ }^{\circ} \mathrm{C}$ (Fig. 3) and the grain size of $\mathrm{ZnO}$ increased markedly from the $32 \mathrm{~nm}$ at $900{ }^{\circ} \mathrm{C}$ to $54 \mathrm{~nm}$ to $1200{ }^{\circ} \mathrm{C}$ (Table S2 $\dagger$ ). Despite the increase in grain size, the weight percentage of $\mathrm{ZnO}$ as estimated from XRD results remained small (few wt\%, Table $\mathrm{S} 2 \dagger$ ) and didn't increase obviously with increased calcination temperature. In addition, the corresponding $\mathrm{Al}_{2} \mathrm{O}_{3}$ phase was not detected, which might be due to the overlap of $\mathrm{ZnAl}_{2} \mathrm{O}_{4}$ and $\mathrm{Al}_{2} \mathrm{O}_{3}$ diffraction peak positions. These results suggest that the phase segregation should be a thermodynamically slow process and might be promoted by the presence of crystals defects (such as dislocations and vacancies) that are introduced during material synthesis. Further improvements in spinel synthesis with controlled defect densities might improve the thermal stability substantially.

The observation and discussions presented above suggest clearly that the formation of PtZn alloy under reducing atmosphere and the phase segregation of $\mathrm{ZnO}$ and $\gamma-\mathrm{Al}_{2} \mathrm{O}_{3}$ from $\mathrm{ZnAl}_{2} \mathrm{O}_{4}$ spinel. In order to better understanding the process, we performed additional experiments with varied Pt loadings with 


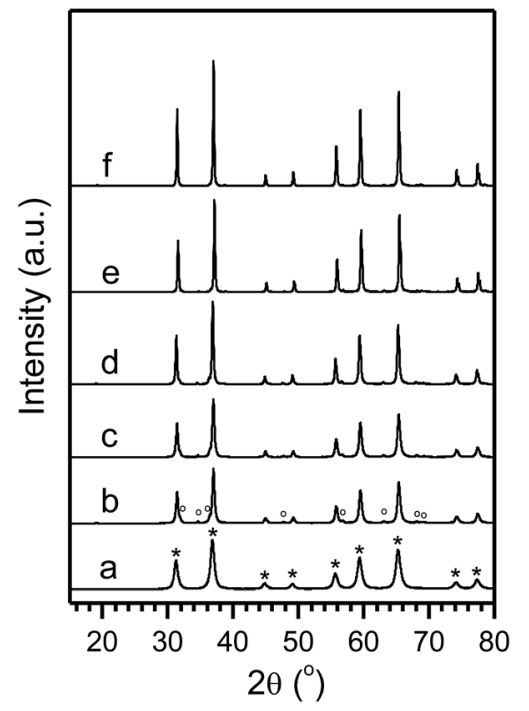

Fig. 3 Set of $\mathrm{XRD}$ results for $\mathrm{ZnAl}_{2} \mathrm{O}_{4}$ samples after calcination at different temperatures: $800{ }^{\circ} \mathrm{C}$ for $12 \mathrm{~h} \mathrm{(a)}$, and further calcination at $900{ }^{\circ} \mathrm{C}$ (b), $1000^{\circ} \mathrm{C}$ (c), $1050{ }^{\circ} \mathrm{C}$ (d), $1100{ }^{\circ} \mathrm{C}$ (e) and $1200^{\circ} \mathrm{C}$ (f) for $2 \mathrm{~h}$. The "*" and "O" marks indicate the diffraction peaks for $\mathrm{ZnAl}_{2} \mathrm{O}_{4}$ spinel and $\mathrm{ZnO}$, respectively.

supports calcinated at different temperature. Fig. 4a shows the XRD of a freshly prepared $5 \mathrm{Pt} / \mathrm{ZnAl}_{2} \mathrm{O}_{4}-800-\mathrm{FR}$ sample $(5 \times \mathrm{Pt}$ loading than samples discussed above). The increases in $\mathrm{Pt}$ loading resulted in substantially stronger diffractions of the PtZn phase than the $1 \mathrm{Pt} / \mathrm{ZnAl}_{2} \mathrm{O}_{4}-800-\mathrm{FR}$. In addition, Fig. $4 \mathrm{~b}$ and $\mathrm{c}$ show results obtained with the $\mathrm{ZnAl}_{2} \mathrm{O}_{4}-900$ support that has $\sim 2.4 \mathrm{wt} \% \mathrm{ZnO}$ and varied Pt loadings of 3, 5 and $8 \mathrm{wt} \%$.

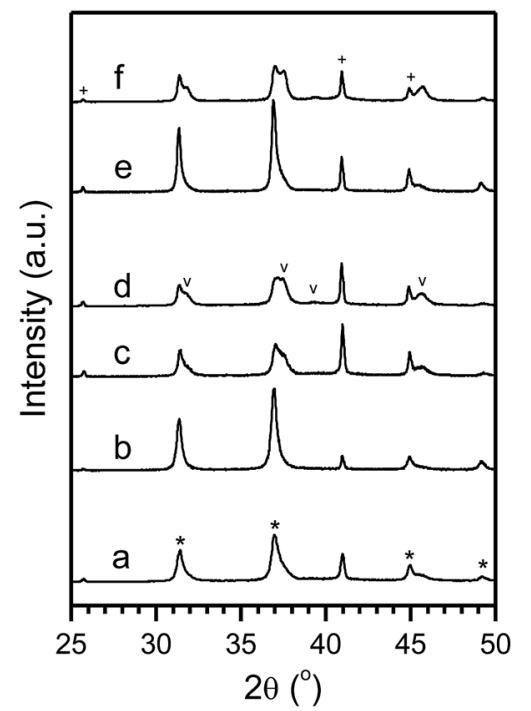

Fig. $4 \mathrm{XRD}$ pattern for $\mathrm{Pt} / \mathrm{ZnAl}_{2} \mathrm{O}_{4}$ samples after reduction in $\mathrm{H}_{2}$ at $800{ }^{\circ} \mathrm{C}$ for $2 \mathrm{~h}$ in which the support was calcined at 800,900 and $1050{ }^{\circ} \mathrm{C}$ before use. (a) $5 \mathrm{Pt} / \mathrm{ZnAl}_{2} \mathrm{O}_{4}-\mathrm{FR}$; (b) $3 \mathrm{Pt} / \mathrm{ZnAl}_{2} \mathrm{O}_{4}-900-\mathrm{FR}$; (c) $5 \mathrm{Pt} / \mathrm{ZnAl}_{2} \mathrm{O}_{4}-900-\mathrm{FR}$; (d) $8 \mathrm{Pt} / \mathrm{ZnAl}_{2} \mathrm{O}_{4}-900-\mathrm{FR}$; (e) $5 \mathrm{Pt} / \mathrm{ZnAl}_{2} \mathrm{O}_{4}-$ 1050-FR, and (f) 8Pt/ZnAl $\mathrm{O}_{4}-1050-\mathrm{FR}$. The "*", "+" and " $\mathrm{V}$ " mark indicate diffraction peaks for $\mathrm{ZnAl}_{2} \mathrm{O}_{4}$ spinel, $\mathrm{PtZn}$ alloy and $\gamma-\mathrm{Al}_{2} \mathrm{O}_{3}$, respectively.
Noticeably, all of these samples exhibited evident diffraction responses from PtZn and $\gamma-\mathrm{Al}_{2} \mathrm{O}_{3}$ and their fractions increased from $0.9,3.7$ to $5.3 \mathrm{wt} \%$ and from 22,61 to $54 \mathrm{wt} \%$ for loadings of 3, 5 and $8 \mathrm{wt} \%$, respectively (Table S3†). Very similar results were found with the $\mathrm{ZnAl}_{2} \mathrm{O}_{4}-1050$ support with Pt loadings of 5 and $8 \mathrm{wt} \%$ (Fig. $4 \mathrm{e}$ and $\mathrm{f}$ and Table $\mathrm{S} 3 \dagger$ ). Interestingly, the estimated lattice constant of the " $\gamma-\mathrm{Al}_{2} \mathrm{O}_{3}$ " phase generated during phase segregation of $\mathrm{ZnAl}_{2} \mathrm{O}_{4}$ was $c=7.93 \AA$, which is slightly higher than the standard ( $c=7.90 \AA$ ). Furthermore, small Pt nanocrystals with sizes less than $3 \mathrm{~nm}$ and very high particle densities were also evident in the STEM images for the freshly prepared samples with higher $\mathrm{Pt}$ loadings $(5 \mathrm{Pt} /$ $\mathrm{ZnAl}_{2} \mathrm{O}_{4}$-FR, Fig. S4; 3Pt/ZnAl ${ }_{2} \mathrm{O}_{4}-900-\mathrm{FR}$, Fig. S5; 5Pt/ $\mathrm{ZnAl}_{2} \mathrm{O}_{4^{-}}$ 1050-FR, Fig. S6 $\dagger$ ). Moreover, almost all of the large particles observed with these samples were PtZn alloys. These observations agree well with Pt stabilization and phase transformations discussed above.

In summary, we demonstrated the superior capability of $\mathrm{ZnAl}_{2} \mathrm{O}_{4}$ spinel $\{111\}$ facet on stabilizing Pt nanocrystals especially under harsh oxidizing and reducing conditions. This discovery together with our previous studies on $\mathrm{MgAl}_{2} \mathrm{O}_{4}$ spinel support solidifies the stabilization mechanism of strong epitaxial interaction of metal-support interfaces, that overall provided a general approach for rational processing of support materials and metal nanocrystals to meet the rigid requirements for specific catalytic reactions. Furthermore, the observations of phase segregation and transformation might have broader implications for alloy type catalyst particles synthesis and stabilization.

\section{Acknowledgements}

This work was supported by the U.S. Department of Energy (DOE), Office of Science, Basic Energy Sciences, Division of Chemical Sciences, Geosciences, and Biosciences (DE-AC05RL01830, FWP-47319). J. Liu and Y. Cheng acknowledge the support from the U.S. Department of Energy, Office of Science, Basic Energy Sciences, Division of Materials Sciences and Engineering, under Award KC020105-FWP12152, for the synthesis of the catalysts and supports. L. Nie acknowledges the support by MS3 Initiative at the Pacific Northwest National Laboratory (PNNL). It was conducted under the Laboratory Directed Research and Development Program (LDRD) at PNNL. The S/TEM and XRD characterizations were performed in the Environmental Molecular Sciences Laboratory (EMSL), a national scientific user facility sponsored by the DOE Office of Biological and Environmental Research, and located at PNNL. PNNL is a multi-program national laboratory operated by Battelle for DOE by Battelle.

\section{References}

1 V. Ponec and G. C. Bond, Catalysis by Metals and Alloys, Elsevier Science, 1995.

2 S. E. Wanke and P. C. Flynn, The Sintering of Supported Metal Catalysts, Catal. Rev., 1975, 12, 93-135. 
3 C. H. Bartholomew, Mechanisms of catalyst deactivation, Appl. Catal., A, 2001, 212, 17-60.

4 W.-Z. Li, K.-Q. Sun, Z. Hu and B.-Q. Xu, Characteristics of low platinum $\mathrm{Pt}-\mathrm{BaO}$ catalysts for $\mathrm{NO}_{x}$ storage and reduction, Catal. Today, 2010, 153, 103-110.

5 H. Shinjoh, M. Hatanaka, Y. Nagai, T. Tanabe, N. Takahashi, T. Yoshida and Y. Miyake, Suppression of Noble Metal Sintering Based on the Support Anchoring Effect and its Application in Automotive Three-Way Catalysis, Top. Catal., 2009, 52, 1967-1971.

6 T. Tanabe, Y. Nagai, K. Dohmae, H. Sobukawa and H. Shinjoh, Sintering and redispersion behavior of Pt on Pt/MgO, J. Catal., 2008, 257, 117-124.

7 P. M. Arnal, M. Comotti and F. Schüth, High-TemperatureStable Catalysts by Hollow Sphere Encapsulation, Angew. Chem., Int. Ed., 2006, 45, 8224-8227.

8 A. Cao, R. Lu and G. Veser, Stabilizing metal nanoparticles for heterogeneous catalysis, Phys. Chem. Chem. Phys., 2010, 12, 13499-13510.

9 S. H. Joo, J. Y. Park, C.-K. Tsung, Y. Yamada, P. Yang and G. A. Somorjai, Thermally stable Pt/mesoporous silica core-shell nanocatalysts for high-temperature reactions, Nat. Mater., 2009, 8, 126-131.

10 I. Lee, Q. Zhang, J. Ge, Y. Yin and F. Zaera, Encapsulation of supported Pt nanoparticles with mesoporous silica for increased catalyst stability, Nano Res., 2010, 4, 115-123.

11 Y. H. Ng, S. Ikeda, T. Harada, T. Sakata, H. Mori, A. Takaoka and M. Matsumura, High Sintering Resistance of Platinum Nanoparticles Embedded in a Microporous Hollow Carbon Shell Fabricated Through a Photocatalytic Reaction, Langmuir, 2008, 24, 6307-6312.

12 J. M. Schwartz and L. D. Schmidt, Microstructures of Pt-Ce and Rh-Ce particles on alumina and silica, J. Catal., 1992, 138, 283-293.

13 J. C. Summers and S. A. Ausen, Interaction of cerium oxide with noble metals, J. Catal., 1979, 58, 131-143.

14 Y. Yin, R. M. Rioux, C. K. Erdonmez, S. Hughes, G. A. Somorjai and A. P. Alivisatos, Formation of Hollow Nanocrystals Through the Nanoscale Kirkendall Effect, Science, 2004, 304, 711-714.
15 W.-Z. Li, L. Kovarik, D. Mei, J. Liu, Y. Wang and C. H. F. Peden, Stable platinum nanoparticles on specific $\mathrm{MgAl}_{2} \mathrm{O}_{4}$ spinel facets at high temperatures in oxidizing atmospheres, Nat. Commun., 2013, 4, 2481.

16 W.-Z. Li, L. Kovarik, D. Mei, M. H. Engelhard, F. Gao, J. Liu, Y. Wang and C. H. F. Peden, A General Mechanism for Stabilizing the Small Sizes of Precious Metal Nanoparticles on Oxide Supports, Chem. Mater., 2014, 26, 5475-5481.

17 X. Duan, D. Yuan, X. Wang and H. Xu, Synthesis and Characterization of Nanocrystalline Zinc Aluminum Spinel by a New Sol-Gel Method, J. Sol-Gel Sci. Technol., 2015, 35, 221-224.

18 X. Y. Chen, C. Ma, Z. J. Zhang and B. N. Wang, Ultrafine gahnite $\left(\mathrm{ZnAl}_{2} \mathrm{O}_{4}\right)$ nanocrystals: hydrothermal synthesis and photoluminescent properties, Mater. Sci. Eng., B, 2008, 151, 224-230.

19 N. A. Pakhomov, R. A. Buyanov, E. M. Moroz, G. R. Kotelnikov and V. A. Patanov, Medium effect in thermal pretreatment on the state and catalytic properties of platinum supported on zinc-aluminium spinel, React. Kinet. Catal. Lett., 1978, 9, 257-263.

20 A. D. Ballarini, S. A. Bocanegra, A. A. Castro, S. R. Miguel and O. A. Scelza, Characterization of $\mathrm{ZnAl}_{2} \mathrm{O}_{4}$ Obtained by Different Methods and Used as Catalytic Support of Pt, Catal. Lett., 2009, 129, 293-302.

21 W. Walerczyk, M. Zawadzki and J. Okal, Characterization of the metallic phase in nanocrystalline $\mathrm{ZnAl}_{2} \mathrm{O}_{4}$-supported $\mathrm{Pt}$ catalysts, Appl. Surf. Sci., 2011, 257, 2394-2400.

22 W. Z. Li, L. Kovarik, D. Mei, J. Liu, Y. Wang and C. H. Peden, Stable platinum nanoparticles on specific $\mathrm{MgAl}_{2} \mathrm{O}_{4}$ spinel facets at high temperatures in oxidizing atmospheres, Nat. Commun., 2013, 4, 2481.

23 R. Pandey, J. D. Gale, S. K. Sampath and J. M. Recio, Atomistic Simulation Study of Spinel Oxides: Zinc Aluminate and Zinc Gallate, J. Am. Ceram. Soc., 1999, 82, 3337-3341.

24 H. Dixit, N. Tandon, S. Cottenier, R. Saniz, D. Lamoen and B. Partoens, First-principles study of possible shallow donors in $\mathrm{ZnAl}_{2} \mathrm{O}_{4}$ spinel, Phys. Rev. B: Condens. Matter Mater. Phys., 2013, 87, 174101. 